\title{
The Danish National Database for Asthma
}

This article was published in the following Dove Press journal:

Clinical Epidemiology

25 October 2016

Number of times this article has been viewed

\author{
Vibeke Backer' \\ Jesper Lykkegaard ${ }^{2}$ \\ Uffe Bodtger ${ }^{3,4}$ \\ Lone Agertoft ${ }^{5}$ \\ Lene Korshoej ${ }^{6}$ \\ Elvira Vaclavik Braüner ${ }^{7,8}$ \\ 'Department of Respiratory \\ Medicine L, Bispebjerg Frederiskberg \\ University Hospital, Copenhagen, \\ ${ }^{2}$ Research Unit of General Practice, \\ Institute of Public Health, University \\ of Southern Denmark, Odense, \\ ${ }^{3}$ Department of Respiratory Medicine, \\ Næstved Hospital, Næstved, ${ }^{4}$ Institute \\ of Regional Health Research, \\ University of Southern Denmark, \\ ${ }^{5} \mathrm{H}$ ans Christian Andersen Children's \\ Hospital, Odense University Hospital, \\ Odense, ${ }^{6}$ Competence Centre for \\ Clinical Quality and Information \\ Technology West (KCKS West), \\ Aarhus, ${ }^{7}$ Research Center for \\ Prevention and Health, Center for \\ Health, Glostrup Hospital, Capital \\ Region of Denmark, Glostrup, \\ ${ }^{8}$ Department of Occupational and \\ Environmental Medicine, Bispebjerg \\ and Frederiksberg Hospital, Capital \\ Region of Denmark, Copenhagen, \\ Denmark
}

Correspondence: Vibeke Backer Department of Respiratory Medicine L, Bispebjerg Frederiskberg University Hospital, Bispebjerg Bakke 23, 2400

Copenhagen, Denmark

$\mathrm{Tel}+45353$ I 3569

Fax +4535312179

Email backer@dadlnet.dk
Aim of the database: Asthma is the most prevalent chronic disease in children, adolescents, and young adults. In Denmark (with a population of 5.6 million citizens), $>400,000$ persons are prescribed antiasthmatic medication annually. However, undiagnosed cases, dubious diagnoses, and poor asthma management are probably common. The Danish National Database for Asthma (DNDA) was established in 2015. The aim of the DNDA was to collect the data on all patients treated for asthma in Denmark and to monitor asthma occurrence, the quality of diagnosis, and management.

Study population: Persons above the age of 6 years, with a specific focus on 6-44 years, are included. The DNDA links three existing nationwide registries of administrative records in the Danish health care system: the National Patient Register, the National Health Insurance Services Register, and the National Prescription Registry. For each year, the inclusion criteria are a second purchase of asthma prescription medicine within a 2-year period (National Prescription Registry) or a diagnosis of asthma (National Patient Register). Patients with chronic obstructive pulmonary disease are excluded, but smokers are not excluded.

Descriptive data: A total of 366,471 prevalent patients with asthma have been identified (year 2014 - as a preliminary test search). This number is in agreement with the estimates of $\sim 400,000$ inhabitants that are available for patients with possible asthma in Denmark. Data encompass the following quality indicators: annual asthma control visits and pharmacological therapy.

Main variables: The variables included are spirometry, as well as tools for diagnosis (including allergy testing), smoking status, height, weight, and acute hospital admissions and unscheduled visits.

Conclusion: DNDA is available from January 1, 2016.

Keywords: indicator, asthma control, asthma management, prescription data, hospital data

\section{Aim of the database}

Asthma is the most prevalent chronic disease in children, adolescents, and young adults living in western societies. ${ }^{1}$ In Denmark, according to the prescription data, the prevalence of asthma is $>400,000$, with an estimated 30,000 new diagnoses per year. However, these figures are questionable, as population studies indicate that substantially more patients have asthma, but also those persons without asthma are incorrectly treated with antiasthma medication. A gold standard diagnostic test for asthma is lacking, although in a specialist setting most asthma cases will be characterized by respiratory symptoms and a positive asthma challenge, whereas primary care often diagnoses asthma based on the symptoms only. ${ }^{2-4}$

The survival rates of treated Danish patients with lung cancer are presently the lowest among the Nordic countries. Therefore, one of the first established Danish submit your manuscript | www.dovepress.com

Dovepress

http://dx.doi.org/10.2147/CLEP.S99494
Clinical Epidemiology 2016:8 60I-606 (Thematic series on clinical quality databases in Denmark) 60 I (c) (7) (5) 2016 Backer et al. This work is published and licensed by Dove Medical Press Limited. The full terms of this license are available at https://www.dovepress.com/terms. cC. you hereby accept the Terms. Non-commercial uses of the work are permitted without any further permission from Dove Medical Press Limited, provided the work is properly attributed. For permission for commercial use of this work, please see paragraphs 4.2 and 5 of our Terms (https://www.dovepress.com/terms.php). 
databases was the lung cancer database. This database was established with the primary task to implement the updated national guidelines and, furthermore, to secure the valid registration of clinical baseline data and quality parameters with the aim of significantly improving the quality of lung cancer surgery. ${ }^{5}$ The effects of this database have been clinically relevant, and follow-up studies have shown an improved clinical practice and core results, reduced mortality, and reduced regional differences. ${ }^{6,7}$ Furthermore, patients suffering from chronic obstructive pulmonary diseases (COPD) have been included in a Danish database, with the primary focus on hospital-based COPD management, ${ }^{8}$ and they have showed an increased quality of care in hospital setting. This is different from an asthma database, which aims to include all patients suffering from asthma.

These data illustrate the need of better quality in the care of the patients with a chronic illness. The occurrence of respiratory symptoms and signs of reversible airway obstruction characterize asthma. Nevertheless, not all patients with respiratory symptoms, such as wheezing, exercise-induced shortness of breath, or cough, should be diagnosed with asthma. ${ }^{9}$ Also a single spirometry is not sufficient to make a correct asthma diagnosis, which preferably should be based on a thorough history of respiratory symptoms and documentation of airway obstruction variability. ${ }^{10}$

In Denmark, most of the prescriptions of antiasthmatic drugs are made in primary care by general practitioners (GPs). However, large numbers of asthma in- and outpatients are treated in tertiary specialist care, ie, secondary care at hospital departments of pulmonology, internal medicine, and pediatrics. This makes it difficult to assess the overall quality of asthma management. To solve this, and in order to establish more accurate monitoring of asthma in the Danish population, in 2015 it was decided to establish a nationwide database of asthma cases in Denmark.

The Danish National Database for Asthma (DNDA) provides a tool to continuously collect and monitor the valid and complete data on the occurrence of asthma in Denmark for the quality of diagnosis and treatment and provide a resource for future epidemiological research in the area of asthma. This database is expected to significantly contribute to the improvement of asthma care in Denmark and, thus, places Denmark on the international forefront of asthma care.

\section{Study population}

The health care system in Denmark is almost universal and generally free of charge, covering all citizens. Since establishment of the Danish Civil Registration System (CRS) ${ }^{11}$ in 1968, all citizens of Denmark have a unique personal identification number (CPR number). All medical, social, and other administrative public records use this unique number to identify citizens; thus, this number allows accurate linkage between registers. The database is based on the existing administrative nationwide records in the Danish health care system and will be maintained by the Danish Clinical Registries (RKKP). This database includes all patients with asthma who were diagnosed, monitored, or treated for the disease anywhere.

The DNDA links three existing nationwide registries of administrative records in the Danish health care system, namely, the National Patient Register (NPR), ${ }^{12}$ the National Health Insurance Services Register (NHISR), ${ }^{13}$ and the National Prescription Registry (NPrR). ${ }^{14}$

- The coverage of the NPR database Version 10 (The International Classification of Diseases [ICD]-10) is $~ 100 \%$ as reporting is compulsory and linked to the allocation of resources.

- The NHISR contains information on all services provided by GPs and specialist practitioners in Denmark. The aim of this register is to administrate reimbursement, thus providing precise service provision, but no information on patient diagnoses or test results. Procedure codes for the conduction of spirometry with and without reversibility test and skin prick test for allergy are available within this registry.

- The NPrR contains information on all prescriptions dispensed at Danish pharmacies. Each record contains among others the CPR number of the individual filling the prescription, as well as date, specific anatomical therapeutic chemical codes of the type of drug, and amount in dosage numbers.

For each year, the inclusion criteria for the DNDA were as follows:

1. All patients older than 6 years were included; however, due to an overlap between the symptoms of asthma and COPD specific, this review focuses on the age group between 6 years and 44 years, at which COPD is very uncommon. Furthermore, the age group $<6$ years has difficulties in performing lung function, and the pattern of symptoms may reflect other diseases than asthma.

2. Second purchase of a prescription drug against asthma (anatomical therapeutic chemical codes R03) within a 2-year period.

3. A hospital record as outpatient, inpatient, or emergency room patient that is coded with either ICD-10 J45 or $\mathrm{J} 46$ (asthma) as primary diagnosis or J45 or J46 as secondary diagnosis in combination with JXX (any 
respiratory disease) or R06 (abnormalities in breathing) as primary diagnosis. All patients with records coded with J44 (COPD) as primary or secondary diagnosis were excluded. However, patients with asthma who smoke were not excluded, and only those who have developed COPD were excluded, as the treatment of this disease and its lung pathology differ from asthma. Individuals were classified as having asthma with a date of inclusion equal to the earliest dates recorded in the NPR or the NPrR. We also use Civil Registration System to obtain information on the date of death or emigration of the patients (Figure 1).

4. In the future, the patients suffering both asthma and COPD, namely, asthma and COPD overlap syndrome, might be included due to participation in both databases.

Patients' contacts with a GP were defined using the NHISR and claim codes relevant for spirometry and allergy tests.

\section{Descriptive data}

A total of 366,471 prevalent patients with asthma have been identified in the year 2014, and similar findings are expected during the following years of data collection.

\section{Main variables}

\section{The indicators selected}

We expect the final database to be available in 2017, with the primary aim of increasing asthma management among children and adults. Data variables will be available for research purposes and will be presented annually in a report issued by the Competency Centre for Clinical Epidemiology and Biostatistics East (KCEB-OE).

The data encompass monitoring the trends in the following quality indicators: first, conduction of annual asthma control visits, pharmacological treatment, forced expiratory volume in 1 second, forced vital capacity, and asthma challenge testing; second, tools used for diagnosis in new cases and the proportion of skin prick tests performed or measurement of specific immunoglobulin E concentrations in new patients; and third, annual assessment of smoking status, height and weight measurements, and the proportion of patients with acute hospital treatment (Table 1).

\section{Follow-up}

Periodic assessments of the quality indicators were carried out and published on a monthly basis in the regional

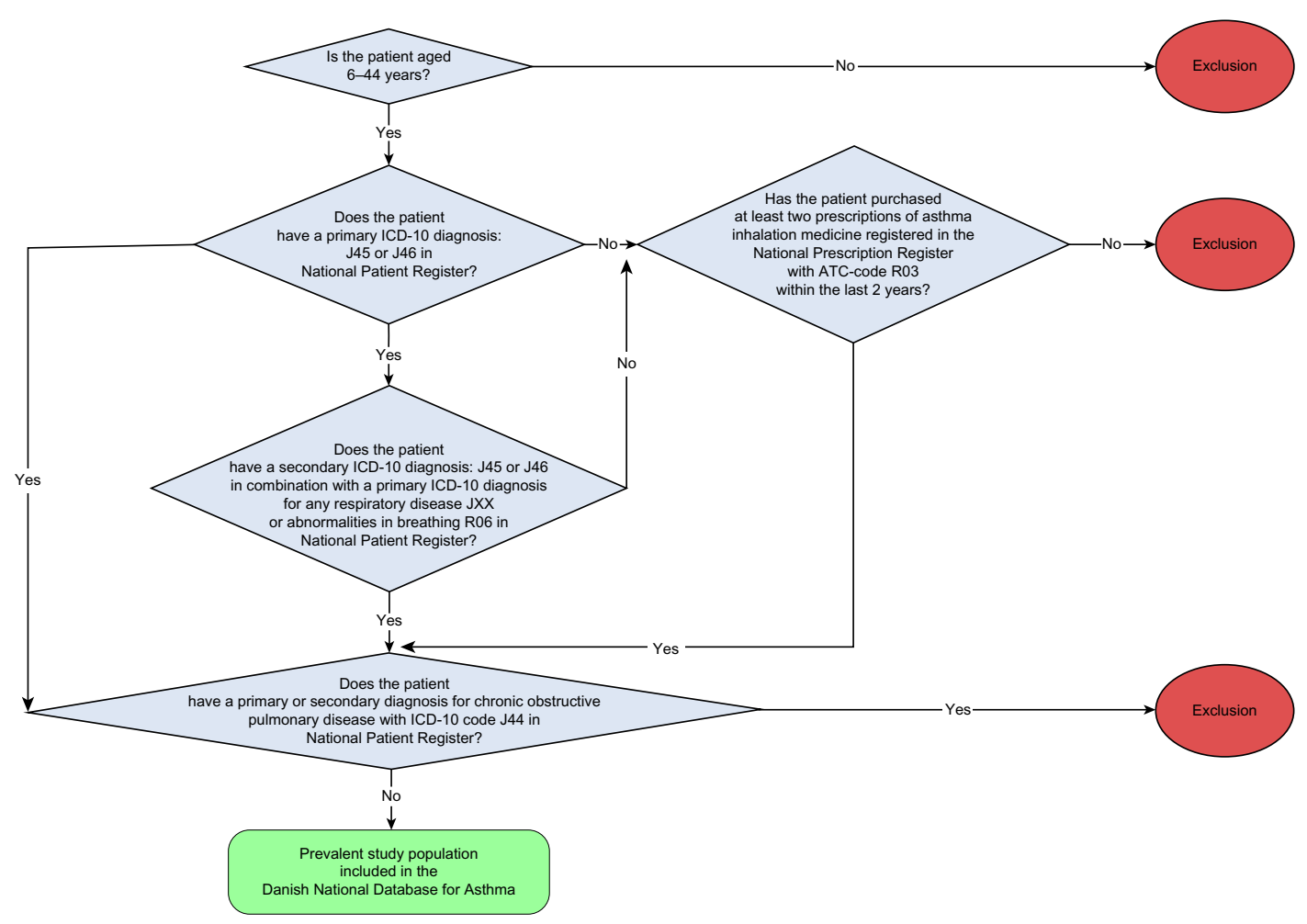

Figure I Study population.

Notes: Study population includes all patients older than 6 years, with a specific focus on the group between 6 years and 44 years. Patients younger than 6 years have difficulties in performing the tests and have a broad pattern of nonasthma respiratory symptoms, and patients older than 44 years might have COPD and not asthma. Abbreviations: ATC, anatomical therapeutic chemical; COPD, chronic obstructive pulmonary disease; ICD-I0, International Cassification of Disease Version I0. 
Table I Description of the included indicator variables for the Danish National Database for Asthma

\begin{tabular}{|c|c|c|}
\hline Area monitored & Research question & Included variables ${ }^{a}$ \\
\hline Patient care & Is the patient monitored annually? & $\begin{array}{l}\% \text { of patients with at least one primary/secondary care visit } \\
\text { for asthma control }\end{array}$ \\
\hline \multirow[t]{2}{*}{$\begin{array}{l}\text { Pharmacological } \\
\text { inhalation treatment }\end{array}$} & $\begin{array}{l}\text { Does the patient's treatment } \\
\text { match the asthma control? }\end{array}$ & $\begin{array}{l}\% \text { of patients purchasing asthma inhalation medicine from the } \\
\text { group of SABA alone at levels equivalent to }>600 \text { doses per } \\
\text { year, with no usage of ICS at the same time }\end{array}$ \\
\hline & $\begin{array}{l}\text { Is the patient receiving the } \\
\text { correct treatment? }\end{array}$ & $\begin{array}{l}\% \text { of patients purchasing asthma inhalation medicine from the } \\
\text { group of LABA or LAMA or LABA/LAMA in combination, } \\
\text { with no usage of ICS at the same time }\end{array}$ \\
\hline \multirow[t]{2}{*}{ Lung function tests } & Is lung function tested annually? & $\begin{array}{l}\% \text { of patients asked to perform } \mathrm{FEV}_{\text {, and FVC lung }} \\
\text { functionality tests at least once yearly among patients with } \\
\text { known asthma }{ }^{\text {b }}\end{array}$ \\
\hline & $\begin{array}{l}\text { Is lung function tested when } \\
\text { diagnosing new patients? }\end{array}$ & $\begin{array}{l}\% \text { of patients asked to perform } \mathrm{FEV}_{1} \text { and FVC lung } \\
\text { functionality tests in a period from } 3 \text { months before till } \\
3 \text { months after first purchase of antiasthmatic prescription } \\
\text { medication in a } 2 \text {-year period or among patients with a new } \\
\text { NPR asthma diagnosis }\end{array}$ \\
\hline Diagnostic tools & $\begin{array}{l}\text { Are the correct diagnostic tools } \\
\text { used among new patients? }\end{array}$ & $\begin{array}{l}\% \text { of patients asked to perform PEF, variability, reversibility, } \\
\text { or challenge test among the newly diagnosed asthma patients } \\
\text { and patients who purchase the first antiasthmatic prescription } \\
\text { medication in a } 2 \text {-year period d,e }\end{array}$ \\
\hline Allergy & $\begin{array}{l}\text { Is allergic response assessed in } \\
\text { newly diagnosed patients? }\end{array}$ & $\begin{array}{l}\% \text { of patients who have been tested for allergy as either total } \\
\text { allergic-specific lgE test or SPT among the newly diagnosed } \\
\text { patients with asthma and patients who purchase the first } \\
\text { antiasthmatic prescription medication in a } 2 \text {-year period }\end{array}$ \\
\hline Smoking status & Is smoking status recorded? & $\begin{array}{l}\% \text { of patients who have been questioned regarding smoking } \\
\text { and passive smoking and passive status at least once yearly } \\
\text { among patients with known asthma }{ }^{b, f, g}\end{array}$ \\
\hline Growth retardation & $\begin{array}{l}\text { Is the patient's weight and height } \\
\text { registered annually? }\end{array}$ & $\begin{array}{l}\% \text { of patients who have had weight and height measured at } \\
\text { least once yearly among patients with known asthma }{ }^{\mathrm{b}, \mathrm{h}}\end{array}$ \\
\hline $\begin{array}{l}\text { Acute hospital } \\
\text { inpatient }\end{array}$ & $\begin{array}{l}\text { Has the patient had emergency } \\
\text { hospital contacts? }\end{array}$ & $\begin{array}{l}\% \text { of patients who had at least one acute hospital inpatient } \\
(<24 \text { hours in duration) visit due to respiratory exacerbations } \\
\text { in the year in question among patients with known asthma }{ }^{b}\end{array}$ \\
\hline
\end{tabular}

Notes: aln all instances, patient's age, sex, date of diagnosis, and primary/secondary care institutions will be available. 'based on the total prevalent population. 'Based on the population included according to the second purchase of asthma inhalation treatment medicine registered in the National Prescription Registry. ${ }^{\mathrm{d}}$ Based on the total incident

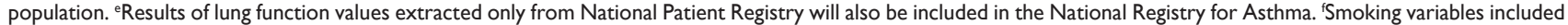
present smoker, number of cigarettes per day for present smokers, ever smokers, never smokers, and patients exposed to passive smoke in home (living with a smoker) or workplace (working in a workplace in which smoking is permitted and at least one colleague smokes). ${ }^{8}$ Data on smoking status only available via National Patient Registry, as the registration of patient smoking by family physicians is not available. hesults of height and weight measurements extracted only from National Patient Registry will also be included in the National Registry for Asthma.

Abbreviations: $\mathrm{FEV}_{1}$, forced expiratory volume in I second; FVC, forced vital capacity; ICS, inhalation corticosteroid; IgE, immunoglobulin E; LABA, long-acting $\beta 2$-agonist; LAMA, long-acting muscarinic receptor antagonist; NPR, National Patient Register; PEF, peak expiratory flow; SABA, short-acting $\beta 2$-agonist; SPT, skin prick test.

information systems, where the clinical units (hospitals, hospital departments, and GPs or specialized practitioners within a specified region) access their own results. All units ensure real-time registration and make use of their own results for further development and quality assurance in the units.

In the future, the database aims to include asthma diagnosis codes and clinical data (forced expiratory volume in 1 second, forced vital capacity, height, weight, and smoking status) registered by GPs and specialized practitioners. A computer software, called Sentinel data capture (http://www. dak-e.dk/flx/en/general-practice/sentinel-data-capture/), is designed to collect these key data as they are entered into the GPs' and specialist practitioners' electronic health record systems. The centralization and access to data collected by Sentinel in regard to patients with asthma is presently being revised.

\section{Potential research}

Although the database is still under establishment, the potential for research into asthma treatment and control is large, including, but not restricted to, geographic and age-related differences in diagnostic tests performed, therapy prescribed, therapy used, health care use, comorbidity, control of visit prevalence, and referral patterns, as well as changes in variable incidences and prevalences over time. 
More specific research areas included were as follows:

- Phase IV pharmaceutical real life trials.

Follow-up studies aimed at the evaluation of the longterm effects of the rearrangement on the Danish health care infrastructure (centralization of smaller hospitals to super hospitals). The database plays an important role in research describing the trends in asthma care in Denmark, including:

- Patient trajectories monitoring in the health care system and the evaluation of why some patients are treated in primary care and others by specialists.

- Factors governing specialist treatment that could provide guidelines for the improvement of specialist treatment selection.

- The influence of comorbidities via linkage to other nationwide Danish health registers.

- The assessment of asthma care quality and patient response as a result of transfer of young patients with asthma from pediatric treatment to adult care. Investigation of long-term trends in asthma and lung function among incorrectly treated patients with asthma.

\section{Strengths and limitations}

The main strength of DNDA is that it centralizes important data pertinent for asthma from three almost complete databases covering the entire Danish population. This centralization provides a potential for quality assessment and research that has never previously been available in one single database.

The main limitation of the database is that, in a given year, patients with asthma in Denmark who do not fulfill the database's criteria are not included. However, these criteria are necessary for the database to primarily include patients for whom the asthma management requirements are fair (Table 1). This is also the reason why patients with asthma and COPD overlap syndrome are not included in the database. The restrictions are based on the pharmacoepidemiological studies. ${ }^{15}$ This overlap between the two obstructive diseases might change in the future, as treatment modalities, such as the new biological drugs to the eosinophilic cells and the cytokines involved, can be used, independent of asthma or COPD and possibly also the overlap between the two diseases. This overlap will be solved in the future, and at present, all pharmaceutical studies are directed toward either asthma or COPD.

Another important issue is the lack of studies validating the asthma diagnosis codes in NPR, however, the database's additional data on tools that are used to diagnose asthma improve the validity of these records. Furthermore, validation studies on NPR diagnosis codes for other diseases, such as COPD, have proven a very high standard. ${ }^{12,16}$

\section{Conclusion}

DNDA is available from January 1, 2016.

\section{Acknowledgments}

This article was funded by the Program for Clinical Research Infrastructure (PROCRIN) established by the Lundbeck Foundation and the Novo Nordisk Foundation and administered by the Danish Regions.

\section{Disclosure}

The authors report no conflicts of interest in this work.

\section{References}

1. Thomsen SF, Ulrik CS, Kyvik KO, et al. The incidence of asthma in young adults. Chest. 2005;127:1928-1934.

2. Nolte H, Nepper-Christensen S, Backer V. Unawareness and undertreatment of asthma and allergic rhinitis in a general population. Respir Med. 2006;100:354-362.

3. Hansen S, Strøm M, Maslova E, Mortensen EL, Granström C, Olsen SF. A comparison of three methods to measure asthma in epidemiologic studies: results from the Danish National Birth Cohort. PLoS One. 2012;7:e36328.

4. Hoffmann-Petersen B, Høst A, Toksvig Larsen K, et al. Prevalence of IgE sensitization in Danish children with suspected asthma. Pediatr Allergy Immunol. 2013;24:727-733.

5. Jakobsen E, Palshof T, Osterlind K, Pilegaard H. Data from a national lung cancer registry contributes to improve outcome and quality of surgery: Danish results. Eur J Cardiothorac Surg. 2009;35: 348-352.

6. Jakobsen E, Green A, Oesterlind K, Rasmussen TR, Iachina M, Palshof T. Nationwide quality improvement in lung cancer care: the role of the Danish Lung Cancer Group and Registry. J Thorac Oncol. 2013;8:1238-1247.

7. Green A, Hauge J, Iachina M, Jakobsen E. The mortality after surgery in primary lung cancer: results from the Danish Lung Cancer Registry ${ }^{\dagger}$. Eur J Cardiothorac Surg. 2016;49:589-594.

8. Lange P. Danish register of chronic obstructive pulmonary disease. Clin Epidemiol. 2016;8:1-5.

9. Lund T, Pedersen L, Larsson B, Backer V. Prevalence of asthma-like symptoms, asthma and its treatment in elite athletes. Scand J Med Sci Sports. 2009;19:174-178.

10. Boulet L-P, FitzGerald JM, Reddel HK. The revised 2014 GINA strategy report: opportunities for change. Curr Opin Pulm Med. 2015;21:1-7.

11. Pedersen CB. The Danish Civil Registration System. Scand J Public Health. 2011;39:22-25.

12. Lynge E, Sandegaard JL, Rebolj M. The Danish National Patient Register. Scand J Public Health. 2011;39:30-33.

13. Sahl Andersen J, De Fine Olivarius N, Krasnik A. The Danish National Health Service Register. Scand J Public Health. 2011;39:34-37.

14. Wallach Kildemoes H, Toft Sorensen H, Hallas J. The Danish National Prescription Registry. Scand J Public Health. 2011;39:38-41.

15. Davidsen JR, Søndergaard J, Hallas J, Siersted HC, Lykkegaard J, Andersen M. Increased use of inhaled corticosteroids among young Danish adult asthmatics: an observational study. Respir Med. 2010;104:1817-1824.

16. Thomsen RW, Lange P, Hellquist B, et al. Validity and underrecording of diagnosis of COPD in the Danish National Patient Registry. Respir Med. 2011;105:1063-1068. 


\section{Publish your work in this journal}

Clinical Epidemiology is an international, peer-reviewed, open access, online journal focusing on disease and drug epidemiology, identification of risk factors and screening procedures to develop optimal preventative initiatives and programs. Specific topics include: diagnosis, prognosis, treatment, screening, prevention, risk factor modification,

Submit your manuscript here: http://www.dovepress.com/clinical-epidemiology-journal systematic reviews, risk \& safety of medical interventions, epidemiology \& biostatistical methods, and evaluation of guidelines, translational medicine, health policies \& economic evaluations. The manuscript management system is completely online and includes a very quick and fair peer-review system, which is all easy to use. 